\title{
A CASE REPORT: THYROTOXIC PERIODIC PARALYSIS: A DIAGNOSTIC CHALLENGE
}

Ashwini G1ㄴ, Ketan L. Pakhale², Archana Bhate ${ }^{3}$

\section{HOW TO CITE THIS ARTICLE:}

Ashwini G, Ketan L. Pakhale, Archana Bhate. "A Case Report: Thyrotoxic Periodic Paralysis: A Diagnostic Challenge". Journal of Evolution of Medical and Dental Sciences 2015; Vol. 4, Issue 19, March 05;

Page: 3379-3382, DOI: $10.14260 /$ jemds/2015/486

\begin{abstract}
Thyrotoxic periodic paralysis (TPP) is an alarming and potentially lethal complication of hyperthyroidism characterised by muscle paralysis and hypokalaemia. A 32 year old Asian male, presented at our institute with bilateral lower limb weakness, which was preceded by heavy exercise. He had no history suggestive of sensory, cranial nerve, bladder or bowel involvement. He had two similar episodes in past 1 year which were mild, recovered within few hours. No family member had similar symptoms. On examination: Pt. had sinus tachycardia, fine tremors. Motor system examination showed the presence of paresis 3/5 of lower limbs. Sensory system examination was within normal limits. Rest of the neurological and systemic examination was otherwise normal. Investigations revealed: Serum electrolyte: Sodium - $138 \mathrm{mEq} / \mathrm{L}$, Potassium - 2.2mEq/L, Chloride $112 \mathrm{mEq} / \mathrm{L}$. Electrocardiogram: sinus tachycardia. Immediate supplementation with Potassium Chloride I.V was given. Recurrent episodes of flaccid paralysis with quick recovery in the hospital were suggestive of a periodic paralysis. On further investigation Thyroid profile was: FT3 - 8.6pmol/L (4 - 7.4), FT4 - 28.7pmol/L (10 - 19), TSH - $0.005 \mathrm{uIU} / \mathrm{ml}(0.4-4.2)$. Anti TPO - $10.2 \mathrm{IU} / \mathrm{ml}(0.00-$ $40.00 \mathrm{IU} / \mathrm{ml}$ ), USG thyroid: normal, Urine electrolytes: normal. The diagnosis at initial presentation was delayed like most cases of TPP because of the subtleness of the clinical features of thyrotoxicosis. Treatments with low-dose potassium supplements, nonselective beta-blockers, and antithyroid drugs were initiated. Patient's follow- up was done after 4weeks with thyroid profile, CBC, electrolytes which were normal. Patient followed up till 6months where he was asymptomatic. Diagnosis requires obtaining a complete history which will result in early diagnosis, appropriate treatment and prevention of severe cardiopulmonary complications. Practitioners should consider obtaining a screening TSH in patients with hypokalaemia periodic paralysis, since it is a curable disorder that resolves when euthyroid state is achieved.
\end{abstract}

KEYWORDS: (TPP) is an alarming, complication, hyperthyroidism, character, muscle paralysis, hypokalaemia, screening TSH, euthyroid.

\section{INTRODUCTION:}

- Thyrotoxic periodic paralysis (TPP) is an alarming and potentially lethal complication of hyperthyroidism characterised by recurrent episodes of muscle paralysis and hypokalaemia.

- Association of periodic paralysis and thyrotoxicosis had been documented by Rosenfeld as early as 1902.

- It is often not recognised when first seen because of lack of familiarity with the disorder and partly due to the subtleness of thyrotoxicosis.

- We hereby report a male patient who presented to us with weakness of bilateral lower limbs. The patient was evaluated and diagnosed to have TPP. 


\section{CASE REPORT}

\section{EPIDEMIOLOGY:}

- Prevalence of Hypokalemic Periodic Paralysis (HPP) is 1 in 100,000 and TPP constitutes 17.3\% of HPP.

- Common in Oriental Asians. Despite a much higher incidence of thyrotoxicosis in women, TPP predominantly affects males of 20-40yrs of age. Male to female ratio ranges from 17:1 to 70:1.

- There are isolated case reports on TPP from India, but there is no comprehensive study about their clinical, laboratory parameters and outcome.

\section{CASE REPORT:}

- A 32 years old male, residing in Maharashtra, presented to our institute, in ED with bilateral lower limb weakness of around 4-5hours duration, acute in onset, below the level of umbilicus, symmetrical, progressing gradually, which was preceded by heavy exercise. He had no history suggestive of sensory, cranial nerve, bladder or bowel involvement. There was no history of trauma, fever, recent vaccination. He recalled two similar episodes in the past 1 year which were mild, recovered within few hours. No family member had similar symptoms.

- On examination: Pt. had pulse: $124 \mathrm{bpm}$, regular, tachycardia, rest of general examination was normal. Clinically thyroid was not enlarged, no signs of hyperthyroid except for fine tremors of hands. Motor system examination showed the presence of flaccid paresis $2 / 5$ of lower limbs with diminished deep tendon reflexes. Sensory system examination was within normal limits. Rest of the neurological and systemic examination was otherwise normal.

- Routine chemistry, ABG and complete blood count in ED revealed normal except for S. Potassium - $2.2 \mathrm{mEq} / \mathrm{L}$. Electrocardiogram (ECG) showed sinus tachycardia with u waves.

- Lumbar spine MRI: normal.

- Immediate supplementation with i.v Potassium Chloride was given at a slow rate. Two hours later, the patient's neurologic symptoms had completely resolved. Recurrent episodes of flaccid paralysis with quick recovery in the hospital were suggestive of a periodic paralysis. Provisional diagnosis of hypokalaemia periodic paralysis was done. Follow up studies were performed to determine the aetiology of the patient's hypokalaemia.

- On further investigation: urine electrolytes: normal.

- Thyroid profile was: FT3 - 8.6pmol/L (4 - 7.4), FT4 - 28.7pmol/L(10 - 19),TSH - $0.005 \mathrm{uIU} / \mathrm{ml}$ (0.4 - 4.2).Anti TPO - $10.2 \mathrm{IU} / \mathrm{ml}(0.00-40.00 \mathrm{IU} / \mathrm{ml}) . \mathrm{USG}$ thyroid: normal.

- Treatment and follow up: low-dose potassium supplements, diet rich in potassium. Non selective beta-blockers tablet propranolol (10) bd. Antithyroid drugs tablet carbimazole (10) tds.

- Patient's follow- up was done after 4weeks with thyroid profile, complete blood count, S. Electrolytes which was normal. Patient followed up till 6 months where he was asymptomatic.

\section{DISCUSSION:}

\section{PATHOGENESIS:}

- It appears that patients with TPP have an underlying predisposition for higher Na-K-ATPase pump number and activity of $\mathrm{Na}$ /K-ATPase activity, either directly by thyroid hormone (most commonly Graves' disease) or indirectly via adrenergic stimulation, insulin, or exercise. 


\section{CASE REPORT}

- This leads to a shift of serum potassium into the intracellular compartment causing hyperpolarization, apparent hypokalemia and muscle weakness, but without changing the total body potassium level.

- The enhanced $\beta$-adrenergic response in thyrotoxicosis further increases $\mathrm{Na} / \mathrm{K}$-ATPase activity and may explain why non-selective $\beta$-adrenergic blockers can abort attacks.

- Insulin-response sequences are present in the upstream region of $\mathrm{Na} / \mathrm{K}-\mathrm{ATPa} e$ genes \&have an exaggerated insulin response \&may explain the association of TPP with carbohydrate-rich meals and sweet snacks.

- Exercise releases potassium from the skeletal muscles, whereas rest promotes influx of potassium. This explains why paralytic attacks occur only during recovery from exercise.

- Recent discovery of a novel mutation in the KCNJ18 gene, which codes for an inwardly rectifying potassium channel and is controlled by thyroid hormones, promotes greater influx of potassium into the cells.

\section{DIAGNOSIS \& TREATMENT:}

- Diagnosis of TPP is based on clinical and biochemical evidence of hyperthyroidism and hypokalaemia in a patient with a history of recurrent episodes of proximal muscle weakness, (lower > upper) sparing of the sensory system, higher mental functions, and cranial nerves. The severity of attacks varies from mild weakness to complete flaccid paralysis Patients can present with respiratory failure, cardiac arrhythmias, and thyrotoxic crisis in severe attacks

- The thyrotoxic symptoms may be absent at the time of attack of TPP in $10-25 \%$ of the patients.This makes diagnosis of TPP more challenging

- Assaying of thyroid function in patients with hypokalaemia paralysis distinguishes thyrotoxic periodic paralysis from other forms of hypokalaemia periodic paralysis. Thyrotoxic periodic paralysis is abolished when thyroid hormones are normalised.

- $\quad$ Treatment of TPP

\section{EMERGENCY THERAPY:}

Potassium replacement: $\mathrm{KCl} 10 \mathrm{mEq} / \mathrm{h}$ i.v and/or KCl 2 g every $2 \mathrm{~h}$, orally. Monitor serum $\mathrm{K}+$ level, avoid rebound hyperkalaemia.

Propranolol 20-80 mg every 8 h, orally.

PREVENTION OF RECURRENT ATTACKS: Avoid precipitating factors (heavy carbohydrate meals, high salt, alcohol, undue exertion) until euthyroidism is achieved.

Definitive therapy of hyperthyroidism with antithyroid drugs/thyroidectomy/radioiodine.

\section{CONCLUSION:}

- The subtlety of the features of hyperthyroidism together with the rarity of this condition makes TPP a difficult condition to diagnose at presentation.

- When a young male of South Asian descent, is initially seen with severe lower limb weakness or paralysis, TPP should be considered in the differential diagnosis and investigated for its presence. 
- Practitioners should consider obtaining a screening TSH in patients, who present with hypokalaemia periodic paralysis, since it is a curable disorder that resolves when euthyroid state is achieved.

\section{REFERENCES:}

1. S. L. Venance, S. C. Cannon, D. Fialho et al., "The primary periodic paralyses: diagnosis, pathogenesis and treatment," Brain, vol. 129, no. 1, pp. 8-17, 2006. View at Publisher, View at Google Scholar, View at PubMed, View at Scopus.

2. Kung AW. Clinical review: Thyrotoxic Periodic paralysis: a diagnostic challenge. J Clin Endocrinol Metab 2006; 91(7): 2490-5.

3. L. Lam, R. J. Nair, and L. Tingle, "Thyrotoxic periodic paralysis," Proceedings (Baylor University. Medical Center), vol. 19, no. 2, pp. 126-129, 2006.

4. J. McFadzean and R. Yeung, "Periodic paralysis complicating thyrotoxicosis in Chinese," The British Medical Journal, vol. 1, no. 538, pp. 451-455, 1967.

5. R. C. Reisin, O. Martinez, M. Moran et al., "Thyrotoxic periodic paralysis in caucasians. Report of 8 cases," Neurologia, vol. 15, no. 6, pp. 222-225, 2000.

\section{AUTHORS: \\ 1. Ashwini G. \\ 2. Ketan L. Pakhale \\ 3. Archana Bhate}

\section{PARTICULARS OF CONTRIBUTORS:}

1. Second year Resident, Department of Medicine, D. Y. Patil University, School of Medicine-Hospital \& Research Centre.

2. Second Year Resident, Department of Medicine, D. Y. Patil University, School of Medicine-Hospital \& Research Centre.
3. Professor \& HOD, Department of Medicine, D. Y. Patil University, School of MedicineHospital \& Research Centre.

\section{NAME ADDRESS EMAIL ID OF THE} CORRESPONDING AUTHOR:

Dr. Ketan L. Pakhale,

Flat No. 407, Harsha Apartment, Amrut Nagar, Ghatkopar (W), Mumbai-400086.

E-mail: drketan.pakhale@gmail.com

Date of Submission: 05/02/2015.

Date of Peer Review: 06/02/2015.

Date of Acceptance: 24/02/2015.

Date of Publishing: 05/03/2015. 